\title{
EVALUASI HIDROLOGI DAERAH ALIRAN SUNGAI WOSI DALAM MENGHADAPI CURAH HUJAN EKSTRIM
}

\author{
Khristian Enggar Pamuji ${ }^{1}$, Hardianti ${ }^{2}$ \\ ${ }^{1,2}$ Prodi Fisika Jurusan Fisika FMIPA UNIPA \\ Jl. Gunung salju Amban, Manokwari - Kode Pos: 98314 \\ e-mail : k_enggar_p@yahoo.com
}

\begin{abstract}
ABSTRAK
Daerah Aliran Sungai Wosi merupakan DAS yang berada di Distrik Manokwari Barat, Kabupaten Manokwari, Papua Barat. Dalam dekade terakhir, DAS Wosi telah menjadi sumber bencana bagi sebagian penduduk yang tinggal di sekitar atau di daerah hilir sungai Wosi. Ketika curah hujan tinggi, Sungai Wosi tidak dapat menampung debit aliran air, sehingga bencana banjir tidak dapat dihindarkan. Penelitian ini bertujuan untuk mengetahui karakteristik DAS Wosi, menentukan kapasitas tampung maksimum sungai dan mengevaluasi peranan atau fungsi hidrologis DAS Wosi dalam mencegah banjir.

Daerah penelitian berada di Daerah Aliran Sungai Wosi Kabupaten Manokwari. Penelitian ini dimulai dengan pengumpulan data serta analisis data primer dan data sekunder. Data yang dikumpulkan berupa data curah hujan Manowkari, dimensi sungai dan data spatial tutupan lahan di DAS Wosi. Data-data tersebut kemudian digunakan untuk mengetahui karakteristik hidrologi sungai, debit puncak aliran dan kapasitas tapung maksimum sungai.

Hasil yang diperoleh menunjukan bahwa pada beberapa titik pengamatan, kapasitas tampung maksimum sungai lebih kecil dari debit puncak aliran permukaan. Debit puncak ini didominasi oleh aliran permukaan yang berasal dari daerah yang tertutup semak belukar/alangalang. Meskipun tutupannya hanya $41 \%$ dari total luasan DAS, namum semak belukar/alangalang telah menyumbang $48 \%$ dari total debit air yang masuk kedalam Sungai Wosi. Hasil evaluasi menunjukan bahwa fungsi hidrologis DAS Wosi sebagai penyangga kejadian puncak hujan dan pengendali banjir saat curah hujan lebat atau ekstrim kurang berfungsi dengan baik.
\end{abstract}

Kata Kunci : Evaluasi hidrologi, DAS Wosi, Kapasitas tampung sungai, Debit puncak aliran permukaan, curah hujan ekstrim

\section{PENDAHULUAN}

Berdasarkan

Peraturan

Pemerintah No 38 Tahun 2011 yang dimaksud dengan sungai adalah alur atau wadah air alami dan/atau buatan berupa jaringan pengaliran air beserta air di dalamnya, mulai dari hulu sampai muara, dengan dibatasi kanan dan kiri oleh garis sempadan. Sedangkan yang dimaksud dengan Daerah Aliran Sungai (DAS) adalah suatu wilayah daratan yang merupakan satu kesatuan dengan sungai dan anak-anak sungainya, yang berfungsi menampung, menyimpan, dan mengalirkan air yang berasal dari curah hujan ke laut secara alami, yang batas di darat merupakan pemisah topografis dan batas di laut sampai dengan daerah perairan yang masih terpengaruh aktivitas daratan.

Daerah Aliran Sungai (DAS) sebagai daerah tangkapan air mempunyai peranan yang penting dalam menyediakan kebutuhan air bagi manusia. Lebih dari itu, DAS berperan penting dalam menjaga lingkungan termasuk menjaga kualitas air, mencegah banjir dan kekeringan saat musim hujan dan kemarau, mengurangi aliran massa (tanah) dari hulu ke hilir. Salah satu upaya untuk menjaga fungsi DAS adalah dengan melakukan pemantauan dan evaluasi terhadap kondisi DAS secara teratur (Tanika L dkk, 2016). 
DAS Wosi merupakan DAS yang berada di Distrik Manokwari Barat, Kabupaten Manokwari, Papua Barat. Dalam beberapa tahun terakhir, DAS Wosi telah menjadi sumber bencana bagi sebagian penduduk Manokwari, terutama yang tinggal di sekitar atau daerah hilir sungai Wosi. Ketika curah hujan tinggi, Sungai Wosi tidak dapat menampung debit aliran air, sehingga bencana banjir tidak dapat dihindarkan.

Alih fungsi lahan sebagai konsekuensi perkembangan kota Manokwari yang semakin pesat, dan munculnya cuaca ekstrim akibat pemanasan global, telah memberikan andil dalam peningkatan kejadian banjir di daerah hilir Sungai Wosi, terutama dalam satu dekade terakhir ini. Untuk menentukan langkah-langkah mitigasi bencana banjir yang tepat, perlu dilakukan evaluasi fungsi hidrologi DAS Wosi, sehingga diperoleh gambaran kondisi DAS saat ini.

Penelitian ini dimaksudkan untuk menjawab permasalahan tersebut. Tujuan dari penelitian ini adalah untuk mengetahui karakteristik DAS Wosi, menentukan kapasitas tampung maksimum sungai (Q) dan mengevaluasi peranan atau fungsi hidrologis DAS Wosi dalam mencegah banjir.

\section{METODE PENELITIAN}

\section{Waktu dan Tempat Penelitian}

Penelitian ini dilakukan selama 4 bulan, dimulai dari bulan Februari 2019 sampai dengan Juni 2019. Daerah penelitian berada di Daerah Aliran Sungai Wosi Kabupaten Manokwari. Penelitian ini dimulai dengan pengumpulan data serta analisis data primer dan data sekunder. Data primer didapat dengan cara melakukan pengukuran dimensi sungai secara langsung pada DAS Wosi. Lokasi koordinat titik-titik pengukuran dapat dilihat pada tabel 1. Dimensi sungai yang diukur meliputi lebar sungai, kedalaman sungai, luas penampang basah, jari-jari hidrolis, dan luas penampang kering. Hasil pengukuran digunkan untuk mengetahui kapasitas tampung maksimum sungai. Lokasi daerah penelitian ditunjukkan pada Gambar 1.

Selain pengukuran fisik sungai, dilakukan juga analisis karakteristik sungai dan tutupan lahan melalui data spasial. Dalam penelitian ini juga menggunakan data sekunder, yaitu data curah hujan bulanan dan data hari hujan selama 14 tahun (tahun 2004 - 2018) di wilayah studi, yang diambil dari Bada Meteorologi Klimatologi dan Geofisika (BMKG), Stasiun Rendani.

Tabel 1. Lokasi Pengukuran Penampang Sungai Wosi

\begin{tabular}{lcc}
\hline \multirow{2}{*}{ Lokasi } & \multicolumn{2}{c}{ Koordinat } \\
\cline { 2 - 3 } & Lintang & Bujur \\
\hline Titik 1 & $0^{\circ} 51^{\prime} 30.94^{\prime \prime} \mathrm{S}$ & $134^{\circ} 2^{\prime} 37.91^{\prime \prime T}$ \\
\hline Titik 2 & $0^{\circ} 51^{\prime} 27.79^{\prime \prime} \mathrm{S}$ & $134^{\circ} 2^{\prime} 33.74^{\prime \prime} \mathrm{T}$ \\
\hline Titik 3 & $0^{\circ} 51^{\prime} 51.65^{\prime \prime} \mathrm{S}$ & $134^{\circ} 2^{\prime} 41.16^{\prime \prime T}$ \\
\hline Titik 4 & $0^{\circ} 51^{\prime} 55.63^{\prime \prime} \mathrm{S}$ & $134^{\circ} 2^{\prime} 04.11^{\prime \prime} \mathrm{T}$ \\
\hline Titik 5 & $0^{\circ} 51^{\prime} 33.65^{\prime \prime} \mathrm{S}$ & $134^{\circ} 2^{\prime} 42.02^{\prime \prime} \mathrm{T}$ \\
\hline
\end{tabular}




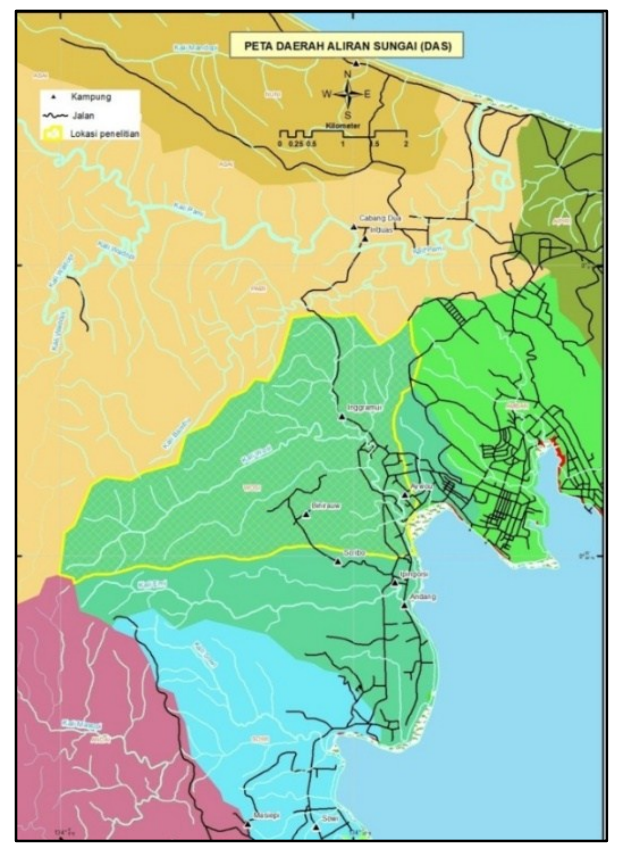

Gambar 1. Peta Daerah Aliran Sungai Kabupaten Manokwari

\section{Pengolahan Data}

\section{a) Karakteristik Sungai}

Perhitungan karakteristik

morfologi atau morfometrik DAS merupakan prasyarat untuk analisis hidrologi yang lebih rinci terhadap DAS.
Data yang digunkan dalam perhitungan karakteritik sungai menggunakan data spasial. Karakteristik morfometrik DAS yang penting untuk diteliti dapat dilihat pada Tabel 2 .

Tabel 2. Perhitungan Karakteristik Morfologi DAS

\begin{tabular}{rlc}
\hline No & \multicolumn{1}{c}{ Parameter } & Persamaan \\
\hline $\mathbf{1}$ & Luas & \\
\hline $\mathbf{2}$ & Keliling & $R_{c}=4 \pi A / P^{2}$ \\
\hline $\mathbf{3}$ & Bentuk DAS & $R_{b}=N_{u} / N_{u+1}$ \\
\hline $\mathbf{4}$ & Rasio Bifurkasi (Bifurcation ratio/Rb) & $R L=L_{u}-L_{u-1}$ \\
\hline $\mathbf{5}$ & Rasio Panjang Sungai $($ Stream Length ratio/RL) & $R_{e}=2 \sqrt{A_{u} / \pi} / L_{b}$ \\
\hline $\mathbf{6}$ & Rasio elongasi (Elongation ratio/Re) & $R_{h}=H / L_{b}$ \\
\hline $\mathbf{7}$ & Rasio relief (Relief ratio/ Rh) & $D d=L / A$ \\
\hline $\mathbf{8}$ & Kerapatan drainage $($ Drainage density/ Dd) & $F_{S}=N_{u} / A$ \\
\hline $\mathbf{9}$ & Frekuensi sungai (Stream frequency/ Fs) & $R_{t}=N_{u} / P$ \\
\hline $\mathbf{1 0}$ & Tekstur drainage (Drainage texture/Rt) & $R_{f}=A / L_{b}^{2}$ \\
\hline $\mathbf{1 1}$ & Faktor bentuk (Form factor/ Rf)
\end{tabular}




\section{b) Debit Puncak}

Debit Puncak ditentukan dari data intensitas curah hujan Kabupaten Manokwari dari tahun 2004 sampai dengan 2018. Berdasarkan data curah hujan tersebut, kemudian dilakukan analisis periode ulang. Periode Ulang adalah waktu hipotetik dimana probabilitas kejadian debit atau hujan dengan besaran tertentu akan disamai atau dilampaui sekali dalam jangka waktu tersebut. Untuk analisis periode ulang, dalam penelitian ini menggunakan metode Log Pearson III seperti berikut :

$$
\log X_{T}=\overline{\log X}+\left(K_{T} S \log X\right)
$$

$\log X_{T}$ : nilai logaritma hujan rencana dengan periode ulang $\mathrm{T}$

$\log X$ : nilai rata-rata dari $\log \mathrm{X}$

$K_{T} \quad$ : faktor frekuensi

SLogX : Standar deviasi $\log \mathrm{X}$

Intensitas curah hujan dihitung menggunakan persamaan Mononobe seperti berikut:

$$
I=\frac{R_{24}}{24}\left(\frac{24}{t_{c}}\right)^{\frac{2}{3}}
$$

dimana:

I : Intensitas curah hujan ( $\mathrm{mm} / \mathrm{jam})$

$\mathrm{t}$ : Lamanya curah hujan / durasi curah hujan (jam)

$R_{24}$ : Curah hujan rencana dalam suatu periode ulang

Perhitungan waktu konsentrasi menggunakan persamaan Kirpich.

$$
t_{c}=\left(\frac{0.87 \times L^{2}}{1000 \times S}\right)^{0.385}
$$

dimana

$t_{c} \quad:$ Waktu konsentrasi (Jam)

L : Panjang saluran air dari titik terjauh sampai titik yang ditinjau $(\mathrm{km})$

$\mathrm{S} \quad$ : Kemiringan rata-rata DAS

Data tutupan lahan digunakan untuk menentukan aliran limpasan (runoff). Metode rasional merupakan metode sederhana yang digunakan dalam penelitian ini untuk memperkirakan aliran puncak limpasan.

dimana

$$
Q_{T}=0.278 x I_{t} x\left(\sum A_{i} x C_{i}\right)
$$

$Q_{T}$ : debit puncak limpasan permukaan pada periode ulang $\mathrm{T}$ tahun

$I_{t}$ : Intensitas curah hujan dengan periode ulang $\mathrm{t}(\mathrm{mm} / \mathrm{jam})$

$\mathrm{C}_{\mathrm{i}}$ : Koefisien limpasan sub daerah pengaliran ke $\mathrm{i}$

$\mathrm{A}_{\mathrm{i}}$ : Luas sub daerah pengaliran ke i $\left(\mathrm{km}^{2}\right)$

\section{c) Kapasitas Tampung Sungai}

Kapasitas tampung maksimum sungai dan saluran drainase dapat diketahui dari persamaan berikut:

Dimana

$$
Q_{S}=\mathrm{Axv}
$$

$Q_{S}:$ Kapasitas tempung sungai $\left(\mathrm{m}^{3} / \mathrm{jam}\right)$

$\mathrm{v} \quad$ : kecepatan aliran $(\mathrm{m} / \mathrm{s})$

A : Luas penampang saluran $\left(\mathrm{m}^{2}\right)$

Kecepatan dapat diperoleh menggunakan persamaan manning :

dimana:

$$
v=\frac{R^{\frac{2}{3}} S^{\frac{1}{2}}}{n}
$$

$\mathrm{n} \quad$ : koefisien kekasaran manning

$\mathrm{R}$ : jari-jari hidrolis $(\mathrm{m})$

$\mathrm{S}$ : kemiringan saluran $(\mathrm{m} / \mathrm{m})$

\section{HASIL DAN PEBAHASAN}

\section{Karakterisitik Daerah Aliran Sungai (DAS) Wosi}

Karakteristik sungai memberikan gambaran atas pola aliran sungai, profil sungai dan genetis sungai. Letak, bentuk dan arah aliran sungai, dipengaruhi antara lain oleh lereng dan ketinggian, perbedaan erosi, struktur jenis batuan, patahan dan lipatan, merupakan faktorfaktor yang menyebabkan perbedaan bentuk genetik dan pola sungai. Pola sungai adalah kumpulan dari sungai yang mempunyai bentuk yang sama, yang dapat menggambarkan keadaan profil dan 
genetik sungainya (Sandy, 1985).

Karakteristik morfometrik sungai dapat dilihat pada Tabel 3 .

Sungai Wosi terletak bermuara di Teluk Wosi (Samudra Pasifik). Dari hasil perhitungan beberapa parameter morfometrik (Tabel 3), Daerah Aliran Sungai (DAS) Wosi memiliki luas 15.2 $\mathrm{km}^{2}$, dengan keliling DAS 18,2 Km. Berdasarkan Peraturan Jenderal Bina Pengelolaan DAS dan Perhutanan Sosial tahun 2013, Daerah Aliran Sungai Wosi masuk katagori DAS berukuran kecil (BPDAS, 2013).

Dilihat dari nilai faktor bentuk (Form factor/ Rf), yaitu rasio luas DAS dengan kuadrat panjang cekungan, DAS Wosi memiliki nilai 0.57 atau bentuk DAS relatif membulat. Selain dari parameter form factor, bentuk DAS juga dapat dilihat dari rasio bifurkasi (Bifurcation ratio), dimana DAS Wosi memiliki rasio bifurkasi sebesar 0.54 . Menurut Soewarno (1991), bentuk daerah aliran sungai yang membulat, debit puncak datangnya lama, begitu juga penurunannya.

Untuk rasio elongasi (Elongation ratio/Re), DAS Wosi memiliki nilai 0.76. Rasio elongasi (Re) didefinisikan sebagai rasio diameter lingkaran dan panjang sungai utama. Rasio elongasi memiliki nilai antara $0-1$. Lebih tinggi nilai rasio elongasi maka bentuknya semakin membulat dan lebih rendah nilai rasio elongasi maka bentuknya semakin memanjang.

Berdasarkan

parameter morfometri rasio elongasi DAS Wosi memiliki bentuk membulat.

DAS Wosi memiliki kerapatan drainase (Dd) $1,4 \mathrm{Km} / \mathrm{Km}^{2}$, artinya setiap $1 \mathrm{~km}^{2}$ area DAS terpadat panjang total sungai $1,4 \mathrm{Km}$. Kerapatan drainase ini termasuk kategori sedang, dimana alur sungai melewati batuan dengan resistensi yang lebih lunak, sehingga angkutan sedimen yang terangkut aliran akan lebih besar. Frekuensi sungai (Stream frequency/ Fs) dan Tekstur drainage (Drainage texturel Rt) DAS Wosi masing-masing 1.58 dan 1.31.

Parameter kerapatan drainase (Dd), Frekuensi Sungai (Fs) dan Tekstur Drainase (Dt) terutama dipengaruhi oleh faktor alami seperti iklim, curah hujan, tutupan vegetasi, jenis batuan, infiltrasi kapasitas tanah, relief dan tahap evolusi bentuk lahan. Distribusi spasial dan intensitas faktor-faktor ini secara bersama-sama atau secara independen mempengaruhi kepadatan drainase suatu DAS, baik dengan meningkatkan kapasitas infiltrasi tanah maupun meningkatkan limpasan permukaan. Jika suatu area DAS dapat menginfiltrasi air hujan dalam jumlah yang signifikan, maka frekuensi aliran dan tekstur drainase akan berkurang (Strahler, A.N, 1964).

Tabel 3. Karakteristik Morfometrik Sungai Wosi

\begin{tabular}{rlr}
\hline $\mathbf{1}$ & Luas $\left(\mathrm{km}^{2}\right)$ & 15,2 \\
\hline $\mathbf{2}$ & Keliling $(\mathrm{km})$ & 18,2 \\
\hline $\mathbf{3}$ & Faktor bentuk (Form factor/ Rf) & 0,574 \\
\hline $\mathbf{4}$ & Bifurcation ratio & 0,54 \\
\hline $\mathbf{5}$ & Rasio elongasi (Elongation ratio/Re) & 0,755 \\
\hline $\mathbf{6}$ & Stream Length ratio & 1,111 \\
\hline $\mathbf{7}$ & Rasio relief (Relief ratio/ Rh) & 0,017 \\
\hline $\mathbf{8}$ & Kerapatan drainage (Drainage density/ Dd) & 1,434 \\
\hline $\mathbf{9}$ & Frekuensi sungai (Stream frequency/ Fs) & 1,579 \\
\hline $\mathbf{1 0}$ & Tekstur drainage (Drainage texture/ Dt) & 1,319 \\
\hline $\mathbf{1 1}$ & Faktor bentuk (Form factor/ Rf) & 0,452 \\
\hline
\end{tabular}


Sungai Wosi memiliki alur sungai yang semakin lebar ke arah hilir. Di daerah hilir alur Sungai Wosi memiliki lebar antara 10-20 m dengan kedalaman 0.5$1.5 \mathrm{~m}$. Pemisah antara badan sungai dan bagian yang datar atau bagian yang tidak tergenangi air (bantaran

sungai) di Sungai Wosi terlihat jelas. Sungai Wosi memiliki tebing yang antara 0.5-4 meter sehingga bisa terlihat jelas adanya bantaran sungai. Bantaran Sungai Wosi sebagian masih ditutup vegetasi (bagian hulu), sebagian sudah ditutupi bangunan (dibagian hilir). Dasar Sungai Wosi sangat bervariasi, ada bagian yang relative datar (dekat muara), dan ada yang landai (daerah tengah), dengan kemiringan (Slope) maksimum hanya $0.5 \%$. Dibagian hulu Sungai, kemiringan lebih tajam ( $>6 \%)$.

Kedalaman sungai sangat tergantung dari jumlah air yang tertampung pada alur sungai yang diukur dari penampang dasar sungai sampai ke permukaan air. Level rataan dasar sungai pengukurannya dirata-ratakan minimal dari tiga titik yang berbeda yaitu di bagian tengah dan kanan kirinya. Kedalaman Sungai Wosi antara $0.2-1.5$ $\mathrm{m}$ (sangat tergantung kondisi curah hujan di bagian hulu),

\section{Kapasitas Tampung Sungai Wosi}

Untuk memperoleh nilai kapasitas tampung maksimum sungai, diperlukan data jari-jari hidrolis ( $\mathrm{R})$, luas penampang basah (A) keliling basah (P), serta koefisien kekasaran manning (n), dimana dalam penelitian ini tipe saluran dan jenis bahannya adalah saluran alam bersih dan berkelok-kelok. Dari data tersebut di peroleh kecepatan Manning, dimana nilai kecepatan diperoleh menggunakan Persamaan Manning dan hasil perhitungan Manning. Nilai kecepatan Manning kemudian digunakan untuk menentukan kapasitas tampung maksimum Sungai Wosi. Berdasarkan perhitungan, kapasitas tampung maksimum sungai dapat dilihat pada Tabel 4.

Nilai Kapasitas tampung maksimum sungai $\mathrm{Q}\left(\mathrm{m}^{3} / \mathrm{jam}\right)$ diperoleh dari kecepatan (v) manning dikalikan dengan luas penampang aliran (A). Kapasitas tampung maksimum sungai terbesar berada pada titik 4 yaitu 26.989 $\mathrm{m}^{3} / \mathrm{jam}$ atau $647.736 \mathrm{~m}^{3} /$ hari.

\section{Debit Puncak Aliran Permukaan}

\section{a) Intensitas Hujan Maksimum}

Secara umum iklim dan cuaca di wilayah Papua Barat sangat dipengaruhi oleh topografi yang tidak datar (berbukit dan bergunung). Hampir seluruh wilayah di Papua Barat memiliki kelas curah hujan tipe III pola $\mathrm{C}$, dengan curah hujan berkisar antara 110,4 - 597,1 mm/bulan. Dari hasil pencatatan Stasiun Badan Meteorologi, Klimatologi, dan Geofisika (BMKG) selama 15 tahun (2004-2018), Manokwari memiliki curah hujan ratarata seperti terlihat pada Tabel 5 .

Tabel 4. Kapasitas Tampung Maksimum Sungai

\begin{tabular}{ccccccrc}
\hline Lokasi & $\mathbf{A}\left(\mathbf{m}^{\mathbf{2}}\right)$ & $\mathbf{P}(\mathbf{m})$ & $\mathbf{R}(\mathbf{m})$ & $\mathbf{V}(\mathbf{m} / \mathbf{s})$ & $\mathbf{Q}\left(\mathbf{m}^{\mathbf{3}} / \mathbf{s}\right)$ & $\mathbf{Q}\left(\mathbf{m}^{\mathbf{3}} / \mathbf{j a m}\right)$ & $\mathbf{Q}\left(\mathbf{m}^{\mathbf{3}} / \mathbf{h a r i}\right)$ \\
\hline Titik 1 & 6.52 & 29.2 & 0.22 & 0.29 & 1.9 & 7.010 & 168.240 \\
\hline Titik 2 & 10.39 & 34.4 & 0.30 & 0.36 & 3.8 & 13.663 & 327.912 \\
\hline Titik 3 & 3.31 & 15.2 & 0.21 & 0.29 & 1.0 & 3.500 & 84.000 \\
\hline Titik 4 & 13.58 & 24.2 & 0.56 & 0.55 & 7.5 & 26.989 & 647.736 \\
\hline Titik 5 & 3 & 16.6 & 0.18 & 0.25 & 0.8 & 2.801 & 67.224 \\
\hline
\end{tabular}


Tabel 5. Rata-rata Curah Hujan, Hari Hujan, dan Kriteria Tipe Hujan di Wilayah Studi Periode 15 Tahun (2004-2018)

\begin{tabular}{lccc}
\hline Bulan & $\begin{array}{c}\text { Curah Hujan } \\
(\mathbf{m m})\end{array}$ & $\begin{array}{c}\text { Hari Hujan } \\
(\text { Hari })\end{array}$ & $\begin{array}{c}\text { Kriteria Tipe Hujan } \\
\text { Menurut Mohr }\end{array}$ \\
\hline Januari & 259.3 & 18 & Bulan Basah \\
\hline Februari & 291.9 & 19 & Bulan Basah \\
\hline Maret & 345.1 & 21 & Bulan Basah \\
\hline April & 218.0 & 18 & Bulan Basah \\
\hline Mei & 168.7 & 15 & Bulan Basah \\
\hline Juni & 149.3 & 15 & Bulan Basah \\
\hline Juli & 139.8 & 14 & Bulan Basah \\
\hline Agustus & 146.9 & 14 & Bulan Basah \\
\hline September & 131.2 & 14 & Bulan Basah \\
\hline Oktober & 108.8 & 13 & Bulan Basah \\
\hline November & 170.4 & 15 & Bulan Basah \\
\hline Desember & 255.8 & 18 & Bulan Basah \\
\hline Jumlah & 2385.1 & 194 & BB=12, BK=0
\end{tabular}

Sumber: Data Primer dari Stasiun BMKG Rendani Manokwari (2004-2018)

Tabel 5 menunjukkan bahwa total rerataan curah hujan selama kurun waktu 15 tahun tergolong tinggi yaitu 2385.1 $\mathrm{mm}$ dengan rerataan hari hujan sebesar 16 hari/bulan. Data tersebut jika diperhitungkan dengan kriteria tipe hujan menurut Mohr, maka semua bulan kategorinya dimasukkan dalam bulan basah, dimana bulan basah dengan curah hujan $>100 \mathrm{~mm}$.

Berdasarkan data curah hujan tersebut, kemudian dilakukan analisis periode ulang. Periode Ulang adalah waktu hipotetik dimana probabilitas kejadian debit atau hujan dengan besaran tertentu akan disamai atau dilampaui sekali dalam jangka waktu tersebut. Untuk analisis periode ulang, dalam penelitian ini menggunakan metode Log Pearson III. Sedangkan Intensitas curah hujan dihitung menggunakan persamaan Mononobe, dengan perhitungan waktu konsentrasi menggunakan persamaan Kirpich.

Waktu yang diperlukan oleh titik air hujan yang jatuh terjauh pada permukaan tanah dalam DAS Wosi yang memiliki luas 1.519 Ha ke saluran terdekat diperkirakan membutuhan waktu 25 jam. Hasil perhitungan Intensitas curah hujan rencana, untuk periode ulang 2 tahun, 5 tahun, 10 tahun, 20 tahun, 50 tahun dan 100 tahun dapat dilihat pada tabel 6 .

\section{b) Koefisien Aliran Permukaan (C)}

Koefisien aliran permukaan diperoleh dari mengacu pada peta tutupan lahan untuk mengetahui luas daerah setiap tata guna lahan tersebut. Peta tutupan lahan dapat dilihat pada Gambar 2.

Tabel 6. Periode Ulang Intensitas Curah Hujan

\begin{tabular}{lcccccc}
\hline Periode Ulang (Tahun) & $\mathbf{2}$ & $\mathbf{5}$ & $\mathbf{1 0}$ & $\mathbf{2 5}$ & $\mathbf{5 0}$ & $\mathbf{1 0 0}$ \\
\hline Intensitas (mm/Tahun) & 2313 & 2899 & 3261 & 3678 & 3973 & 4264 \\
\hline Intensitas (mm/Hari) & 13,9 & 17,4 & 19,5 & 22,1 & 24,0 & 25,8 \\
\hline
\end{tabular}




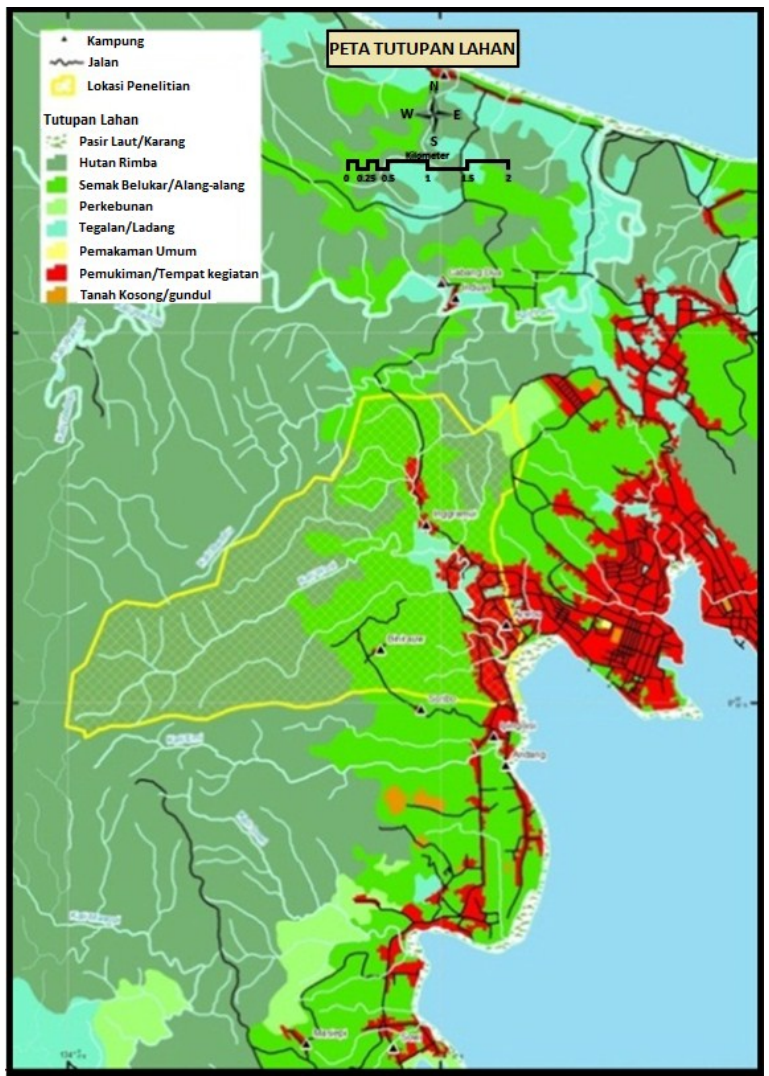

Gambar 2 Peta Tata Guna Lahan DAS Wosi, Kabupaten Manokwari

Berdasarkan peta tata guna lahan,

DAS Wosi dapat dikelompokkan ke dalam beberapa penggunaan lahan yang luas masing-masing lahan dapat dilihat pada Tabel 7.

DAS Wosi terdiri dari hutan, semak belukar, perkebunan, ladang dan pemukiman. Daerah hutan berada pada kemiringan $10-20 \%$ (perbukitan) dengan luas daerah $10.093 .750 \mathrm{~m}^{2}$. Sehingga nilai koefisien aliran permukaan diperkirakan 0,36. Tutupan lahan berupa Semak belukar pada kemiringan 10-20\% (perbukitan) dengan luas $8.453 .125 \mathrm{~m}^{2}$ dengan nilai koefisien aliran permukaan 0,54. Daerah Perkebunan dengan kemiringan $1-10 \% \quad$ (bergelombang) dengan luas daerah $156.250 \mathrm{~km}^{2}$ sehingga nilai koefisien aliran permukaan 0,35. Pada daerah ladang memiliki kemiringan 1\% (datar) dengan luas daerah 453.125 $\mathrm{m}^{2}$ dengan nilai koefisien aliran permukaan 0,22. Dan pada daerah pemukiman dengan kemiringan 10-20\% (perbukitan) dengan luas daerah $1.734 .375 \mathrm{~m}^{2}$ sehingga nilai koefisien aliran permukaan diperkirakan adalah 0,75 . Dari data di atas dapat diketahui bahwa kondisi tata guna lahan pada DAS Wosi didominasi daerah Hutan dan Semak Belukar. Koefisien aliran permukaan berdasarkan fungsi lahan dalam persentase dapat dilihat pada Gambar 3.

Tabel 7. Data Penggunaan Lahan pada DAS Wosi

\begin{tabular}{llcc}
\hline Tutupan Lahan & \multicolumn{1}{c}{ Topografi } & Luas Daerah $\left.\mathbf{( m}^{2}\right)$ & Nilai C \\
\hline Hutan & Perbukitan $(10-20 \%)$ & 10.093 .750 & 0,36 \\
\hline Semak belukar & Perbukitan $(10-20 \%)$ & 8.453 .125 & 0,54 \\
\hline Perkebunan & Bergelombang $(1-10 \%)$ & 156.250 & 0,35 \\
\hline Ladang & Datar $(1 \%)$ & 453.125 & 0,22 \\
\hline Pemukiman & Perbukitan $(10-20 \%)$ & 1.734 .375 & 0,75 \\
\hline
\end{tabular}




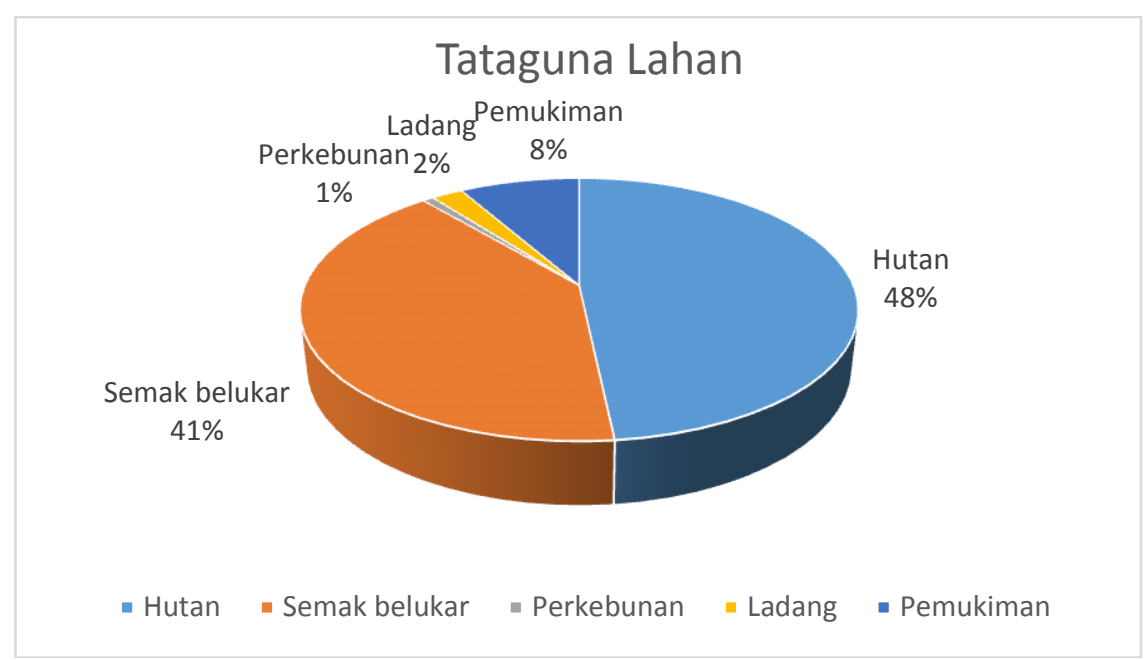

Gambar 3. Prosentase Tataguna Lahan

\section{c) Debit Puncak Aliran Permukaan}

Dengan memperhitungkan luas tutupan lahan, koefisien run-off dan intensitas curah hujan, maka hasil perhitungan debit puncak aliran permukaan dapat dilihat pada Tabel 9. Debit puncak aliran permukaan yang mengalir di Sungai Wosi mencapai $38.360,9 \mathrm{~m}^{3} /$ hari untuk periode ulang 2 tahun, dan untuk periode ulang 50 tahu mencapai $165.184,4 \mathrm{~m}^{3} /$ hari. Debit ini didominasi oleh aliran permukaan yang berasal dari daerah yang tertutup semak belukar/alang-alang. Meskipun tutupannya hanya $41 \%$ dari total luasan DAS, namum semak belukar/alang-alang telah menyumbang $48 \%$ dari total debit air yang masuk kedalam Sungai Wosi.

Tabel 8. Luasan, Intensitas Curah Hujan dan Koefisien Run-off

\begin{tabular}{|c|c|c|c|c|c|c|}
\hline \multirow{2}{*}{ Tutupan Lahan } & \multirow[t]{2}{*}{ Luas $\left(\mathrm{m}^{2}\right)$} & \multicolumn{4}{|c|}{$\begin{array}{c}\text { Intensitas Curah Hujan (mm/hari) } \\
\text { dengan Periode Ulang }\end{array}$} & \multirow[t]{2}{*}{$\begin{array}{l}\text { Koefisien } \\
\text { run-off }\end{array}$} \\
\hline & & 2 thn & 5 thn & 25 thn & 50 thn & \\
\hline Hutan & 10.093 .750 & 13,9 & 17,4 & 22,1 & 24 & 0.36 \\
\hline Semak belukar/Alang-alang & 8.453 .125 & 13,9 & 17,4 & 22,1 & 24 & 0.55 \\
\hline Perkebunan & 156.250 & 13,9 & 17,4 & 22,1 & 24 & 0.35 \\
\hline Ladang/Tegalan & 453.125 & 13,9 & 17,4 & 22,1 & 24 & 0.22 \\
\hline Permukiman & 1.734 .375 & 13,9 & 17,4 & 22,1 & 24 & 0.75 \\
\hline
\end{tabular}

Tabel 9. Hasil Perhitungan Debit Puncak Aliran Permukaan

\begin{tabular}{lrrrr}
\hline \multirow{2}{*}{ Tutupan Lahan } & \multicolumn{4}{c}{ Debit Rencana $\left(\mathrm{m}^{3} /\right.$ hari $)$} \\
\cline { 2 - 5 } & 2 Tahun & 5 Tahun & 25 Tahun & 50 Tahun \\
\hline Hutan & $35.851,4$ & $44.640,5$ & $56.689,2$ & $61.638,0$ \\
\hline Semak belukar/Alang-alang & $1.911,3$ & $2.379,8$ & $72.531,2$ & $78.863,1$ \\
\hline Perkebunan & 22,5 & 28,0 & 853,2 & 927,6 \\
\hline Ladang/Tegalan & 41,0 & 51,0 & $1.555,2$ & $1.691,0$ \\
\hline Permukiman & 534,7 & 665,8 & $20.293,1$ & $22.064,7$ \\
\hline Total & $38.360,9$ & $47.765,1$ & $151.921,9$ & $165.184,4$ \\
\hline
\end{tabular}




\section{d) Debit Puncak Saat Curah hujan Ekstrim}

Yang dimaksud dengan Curah Hujan Ekstrim adalah berupa hujan lebat dan hujan es. Hujan Lebat adalah hujan dengan intensitas paling rendah 50 (lima puluh) milimeter $(\mathrm{mm}) / 24$ (dua puluh empat) jam dan/atau 20 (dua puluh) milimeter (mm)/jam (BMKG, 2010). Jika terjadi curah hujan ekstrim dengan intensitas > $50 \mathrm{~mm} /$ hari, maka debit puncak aliran permukaan dapat mencapai lebih besar dari $344.422 \mathrm{~m}^{3} /$ hari.

\section{Perbandingan Nilai Debit Puncak (Qp) dan Kapasitas Tampung Maksimum Sungai (Q) \\ Perbandingan kapasitas tampung} maksimum sungai dengan debit puncak pada DAS Wosi dapat dilihat pada tabel
10. Dari tabel tersebut dapat dilihat bahwa, titik 1 memiliki kapasitas tampung maksimum sungai 168.240 $\mathrm{m}^{3} /$ jam. Titik 1 dan titik 2 masih dapat menampung debit puncak untuk curah hujan rencana 50 tahun, akan tetapi tidak bisa menampung debit sungai ketika terjadi curah hujan ekstrim. Untuk dapat menampung curah hujan ekstrim, kapasitas tampung titik pertama harus dinaikan hingga dua kali lipat.

Titik ke 3 dan ke 5 dapat menampung debit aliran sungai untuk debit rencana 5 tahun, tapi tidak dapat menampung debit rencana 25 tahun dan saat curah hujan ekstrim. Satu-satunya titik pengamatan yang masih dapat menampung curah hujan ektrim adalah titik ke 4, dimana kapasitas tampung maksimumnya mencapai 647.736 $\mathrm{m} 3 /$ hari.

Tabel 10. Perbandingan Nilai Debit Puncak dan Kapasitas Tampung Maksimum SungaiWosi

\begin{tabular}{|c|c|c|c|c|c|c|}
\hline \multirow[t]{2}{*}{ Lokasi } & \multirow{2}{*}{$\begin{array}{c}\mathbf{Q} \\
\left(\mathbf{m}^{3} / \text { hari) }\right.\end{array}$} & \multicolumn{5}{|c|}{$\begin{array}{l}\text { Debit saat intenitas curah hujan rencana dan ekstrim } \\
\qquad\left(\mathrm{m}^{3} / \mathrm{hari}\right)\end{array}$} \\
\hline & & 2 Tahun & 5 Tahun & 25 Tahun & 50 Tahun & Ekstrim \\
\hline Titik 1 & 168.240 & \multirow{5}{*}{38.361} & \multirow{5}{*}{47.765} & \multirow{5}{*}{151.922} & \multirow{5}{*}{165.184} & \multirow{5}{*}{$>344.423$} \\
\hline Titik 2 & 327.912 & & & & & \\
\hline Titik 3 & 84.000 & & & & & \\
\hline Titik 4 & 647.736 & & & & & \\
\hline Titik 5 & 67.224 & & & & & \\
\hline
\end{tabular}




\section{KESIMPULAN}

1. Daerah Aliran Sungai Wosi merupakan DAS kecil dan memiliki bentuk DAS yang membulat, sehingga debit puncak datangnya lama, begitu juga penurunannya.

2. Kapasitas tampung maksimum sungai terbesar berada pada titik 4 yaitu $26.989 \mathrm{~m}^{3} / \mathrm{jam}$ atau 647.736 $\mathrm{m}^{3} /$ hari.

3. Pada beberapa titik pengamatan, kapasitas tampung maksimum sungai lebih kecil dari debit puncak aliran permukaan. Debit puncak ini didominasi oleh aliran permukaan yang berasal dari daerah yang tertutup semak belukar/alang-alang. Meskipun tutupannya hanya $41 \%$ dari total luasan DAS, namum semak belukar/alang-alang telah menyumbang $48 \%$ dari total debit air yang masuk kedalam Sungai Wosi.

4. Hasil evaluasi menunjukan bahwa fungsi hidrologis DAS Wosi sebagai penyangga kejadian puncak hujan dan pengendali banjir saat curah hujan ekstrim akan berkurang.

\section{DAFTAR PUSTAKA}

Peraturan Direktur Jenderal Bina Pengelolaan Daerah Aliran Sungai Dan Perhutanan Sosial Nomor : P.
3/V-SET/2013 Tentang Pedoman Identifikasi Karakteristik Daerah Aliran Sungai

Peraturan Pemerintah No 38 Tahun 2011 Tentang Sungai.

Sandy, I.M. 1985. DAS-Ekosistem Penggunaan Tanah. Publikasi Direktorat Taguna Tanah Departemen Dalam Negeri (Publikasi 437).

Soewarno, 1991, Hidrologi Pengukuran dan Pengolahan Data Aliran Sungai (Hidrometri), Nova, Bandung.\#

Tanika L, Rahayu S, Khasanah N, Dewi S. 2016. Fungsi Hidrologi pada Daerah Aliran Sungai (DAS): Pemahaman, Pemantauan, dan Evaluasi. Bahan Ajar 4. Bogor, Indonesia: World Agroforestry Centre (ICRAF) Southeast Asia Regional Program.

Strahler, A. (1964) Quantitative Geomorphology of Drainage Basins and Channel Networks. In: Chow, V., Ed., Handbook of Applied Hydrology, McGraw Hill, New York.

Peraturan Kepala Badan Meteorologi, Klimatologi, Dan Geofisika Nomor : KEP. 009 Tahun 2010 Tentang Prosedur Standar Operasional Pelaksanaan Peringatan Dini, Pelaporan, dan Diseminasi Informasi Cuaca Ekstrim.

http://jdih.bmkg.go.id/ 